\title{
MATURIDADE ÉTICA E IDENTIDADE MORAL: a construção na prática pedagógica
}

\author{
Ethical maturity and moral identity: \\ educational activity construction
}

\section{Maria Judith Sucupira da Costa Lins}

Professora adjunta da Faculdade de Educação da Universidade Federal do Rio de Janeiro (UFRJ), Rio de Janeiro, RJ - Brasil, mariasucupiralins@terra.com.br

\section{Resumo}

Este artigo focaliza o problema de educar uma pessoa para a Maturidade Ética e a Identidade Moral. Maturidade Ética diz respeito ao ponto em que uma pessoa pode entender valores e agir de acordo com estes. Identidade Moral define uma pessoa que sabe quem ele ou ela é e que age de acordo com esta consciência. Maturidade Ética e Identidade Moral não são dons naturais e devem ser desenvolvidos por meio da Educação. Escolas devem refletir sobre programas de Educação Moral no currículo dos alunos com a finalidade de lhes oferecer a oportunidade de construir estas duas categorias. Pode ser dito que há Identidade Moral quando uma pessoa rege sua vida sobre valores morais. Identidade Moral revela que uma pessoa desenvolveu a maturidade ética.

Palavras-chave: Ética. Educação moral. Valores. Identidade moral. Maturidade ética.

Rev. Diálogo Educ., Curitiba, v. 9, n. 28, p. 633-649, set./ dez. 2009 


\begin{abstract}
This article focuses the problem of educating a person for Ethical Maturity and Moral Identity. Ethical Maturity concerns to the point a person can understand values and act according to them. Moral Identity defines a person who knows who he or she is and acts according to this consciousness. Both Ethical Maturity and Moral Identity are not natural gifts and because of this, they must be developed through Education. Schools should think about Moral Education programs in students' curriculum in order to provide them the opportunity to construct these two categories. It can be said that there is Moral Identity when a person rules her or his life upon moral values. Moral Identity reveals that a person has developed ethical maturity.
\end{abstract}

Keywords: Ethics. Moral education. Values. Moral identity. Ethical maturity.

\title{
INTRODUÇÃO
}

Este artigo pretende suscitar a reflexão concernente a dois conceitos altamente instigantes para o educador: Maturidade Ética e Identidade Moral. D ois conceitos, ou melhor, duas expressões, que são frequentemente utilizadas por pessoas interessadas no desenvolvimento ético e moral dos estudantes.

Com o objetivo de provocar uma discussão, tentaremos analisar o conteúdo destas expressões e expor algumas ideias que vêm sendo elaboradas como resultado de pesquisas sobre educação moral e comportamento ético por nós realizadas. E , ainda, este objetivo se amplia, na medida em que pretendemos não só entender o significado das expressões, como principalmente observar a sua construção na prática pedagógica. Ambas as categorias são apresentadas como fundamentais para o pleno desenvolvimento dapessoa. Consideramoso desenvolvimento da pessoa notadamente influenciado pela Educação, por isso Maturidade Ética e Identidade Moral serão analisados numa perspectiva pedagógica.

Em que a Educação se relaciona aos dois conceitos aqui destacados? Compreendemos que o processo educativo pretende transformar a pessoa, partindo de suas potencialidades, de modo que

Rev. Diálogo Educ., Curitiba, v. 9, n. 28, p. 633-649, set./ dez. 2009 
estas cheguem à condição de atos, e estes atos revelem cada vez mais o seu aperfeiçoamento. Sabemos que este processo nos mostra a pessoa sempre caminhando para um estado de perfeição inatingível, estado este que se coloca na posição de ideal norteador de toda a Educação. Para o aperfeiçoamento da pessoa, aqui referido, estas duas categorias são fundamentais.

D estacamos aqui estas duas categorias para a nossa reflexão, num recorte que visa ampliar a compreensão de seu papel no conjunto de todos os outros elementos componentes da atividade educativa. Sendo a E ducação uma práxis extremamente complexa e derivada de um profundo pensar filosófico, certamente que não esgotaremos o assunto. No entanto, consideramos que este deve ser abordado, com o intuito de se oferecer uma contribuição para a importante discussão sobre a melhor formação da pessoa, interesse este de todos nós educadores.

Maturidade É tica é uma expressão difícil de ser definida. $\mathrm{Na}$ realidade se trata de um grande desafio para nós, de modo que se constituiu no cerne da pesquisa que ora conduzimos sobre o jovem estudante de curso de preparação de professores de ensino fundamental, 0 antigo curso normal. ${ }^{1}$ Neste artigo, a ideia de Maturidade Ética será analisada a partir de diferentes perspectivas. Há na verdade aqui muito mais uma proposta de diálogo do que de apresentação de ideias prontas, tanto sobre a expressão, em questão, como sobre quaisquer outros elementos. Maturidade Ética não tem sido um campo de pesquisa frequente, como se pode observar numa consulta a <http:// www.eric.ed.gov>, que aponta zero resultados sobre este tema, em todos os campos, em publicações de janeiro de 1879 a novembro de 2007 numa das mais expressivas revistas científicas de Pesquisa Educacional que é a American Educational Research Journal.

Encontramos referência a este tema, com pequena alteração da denominação, no Journal of Moral E ducation, dentreas quais salientamos o estudo de McD onough (2005). A expressão Identidade M oral, que será usada no presente texto, muitas vezes também pode ser entendida como Identidade Ética, principalmente por causa da circunstância da atual legislação brasileira, que a partir dos Parâmetros Curriculares Nacionais de 1997, substituiu a denominação Educação Moral por Ética. Na literatura pertinente, a expressão Identidade $\mathrm{M}$ oral é encontrada mais

Pesquisa iniciada em março de 2007 no G rupo de Pesquisa sobre Ética e E ducação (G PEE) da Faculdade de Educação da UFRJ.

Rev. Diálogo Educ., Curitiba, v. 9, n. 28, p. 633-649, set./ dez. 2009 
frequentemente, no entanto, precisamos fazer a sinonimização para que haja uma adequação às recomendações existentes no texto dos Parâmetros Curriculares Nacionais.

$\mathrm{Na}$ realidade, muitas vezes, conforme consulta nas principais revistas internacionais que tratam do tema, ${ }^{2}$ a Identidade é relacionada à Moral, mas não há muitas ocorrências das duas palavras juntas, formando a expressão que é o foco deste trabalho. Preocupados em cunhar esta expressão, de grande importância pedagógica, estamos neste trabalho empenhados em investigar seu significado. Entender qual é este significado e buscar reconhecer a sua presença nos jovens se torna, pois, um dos objetivos aqui pretendidos.

Identidade Moral, de modo simples e direto, é o que define uma pessoa em profundidade com referência ao domínio da ética e a consciência de si mesma. Alguém que chegue a construir a sua identidade ética sabe quem é e age de acordo com esta consciência. 0 educador procura acompanhar os passos desta construção, principalmente na prática pedagógica, sempre com a finalidade de permitir ao educando, por meio de sua liberdade, encontrar esta Identidade Moral.

A hipótese que nos desafia a pesquisar sobre a Identidade Moral e sua construção na prática pedagógica é bastante simples. Começamos com a pergunta: O que é Identidade Moral? Uma vez explicada esta expressão, consideramos que a construção da Identidade Moral acontece também na escola. Com isso não estamos excluindo todos os outros elementos participantes nesta construção. Também não afirmamos que a escola seja o único espaço no qual a Identidade Moral será construída. Esta hipótese não pretende afastar outras ideias sobre 0 assunto. Em artigos diversos, a Identidade Moral pode ser buscada em situações específicas, tais como a ação da família, das comunidades de bairro, dos meios de comunicação, dos espaços de lazer e recreação ou no trabalho. Estabelecemos o recorte da construção da Identidade Moral na prática pedagógica visando oferecer aos professores subsídios para a sua reflexão que os ajudem no dia-a-dia da escola.

D e certa forma, não encontramos exatamente um conceito isolado para esta expressão, mas análises e deduções que levam a uma associação tal que permita a sua compreensão. Tentaremos clarificar o que está contido nestas palavras, o que se exige para que venham a adquirir um significado e também queremos reconhecer os elementos que podem

Disponível em: < http:/ / aerj.aera.net> ou <http:/ / www.eric.ed.gov> . Acesso em: 09 set. 2009.

Rev. Diálogo Educ., Curitiba, v. 9, n. 28, p. 633-649, set./ dez. 2009 
favorecer esta construção. Pode-se, também, denominar esta aquisição, pois a Identidade Moral não faz parte do patrimônio inato do sujeito, tratando-se desta forma de algo que posteriormente aparecerá. Fica difícil dizer que será adquirido, pois na realidade será a mais íntima constituição do próprio sujeito que se afirmará como esta Identidade Moral.

Os estudos sobre Identidade despertam interesse, de modo geral. Encontramos, no entanto, uma abordagem direta quanto a uma exploração sobre o significado de Identidade Moral. Trata-se do texto de D aniel Hart (1997, p. 165), que explica:

\begin{abstract}
Identidade M oral se encontra em duas tradições teóricas. Tentativas para caracterizar as essências da moralidade e para entender as origens das inclinações morais; e a promoção da busca de uma vida moral são encontradas ao longo das histórias da filosofia e da psicologia.
\end{abstract}

Estas tradições nos ensinam que foram construídas teorias sobre Moral propriamente e sua relação com a organização da vida pessoal baseada neste conhecimento, mas não há uma indicação de estudos sobre a Identidade Moral especificamente.

Este estudo se situa numa perspectiva nova, na medida em que precisamos conhecer o amadurecimento de nossos alunos no que diz respeito à vivência do processo educativo moral ao mesmo que estes constroem a sua Identidade Moral. A conquista da maturidade destes alunos, 0 que revela o final da adolescência ea entrada na idade adulta, além dos aspectos de Moral traz também todos os outros componentes da personalidade. No entanto, ficaremos restritos em nossas análises ao domínio da moral. Q uando nos referimos ao final da adolescência, estamos conscientes da imensa dificuldade existente hoje em dia da determinação deste momento. Autores como Tony Anatrella (1991) pesquisaram comportamentos, sentimentos e principalmente 0 autoconhecimento de jovens e este encontrou um estado de prolongamento da adolescência que retarda a entrada destes na idade adulta. Entende-se que a maturidade está se tornando cada vez mais um complexo processo e que a Identidade resultante não se consegue sem um esforço muito maior.

A maturidade, do ponto de vista psicológico, está entrelaçada com a aquisição da identidade. Assim, também a Identidade Moral será analisada em relação ao processo de maturação psicológica pelo qual uma criança deve passar até sua conclusão no final da adolescência, seja este quando for. Pode-se deste modo falar em maturidade ética, ou, 0 que pensamos ter o mesmo significado, maturidade moral.

Rev. Diálogo Educ., Curitiba, v. 9, n. 28, p. 633-649, set./ dez. 2009 
0 que é maturidade moral? Esta pergunta será o fio condutor desta reflexão. Mesmo que não completamente, há uma intenção de que se chegue a um elenco de características capazes de nos mostrar um retrato de uma pessoa moralmente madura. Uma pessoa que encontrou a sua Identidade Moral.

\section{Chegamos a uma outra pergunta:}

Identidade moral se assemelha à maturidade moral?

Uma coisa quer dizer a mesma que a outra?

São questões abertas que não podem ser resolvidas rapidamente. A discussão está iniciada, não temos a pretensão de chegar a uma conclusão fechada, mas apenas de participar dos estudos so bre este tema.

D e alguma forma, como procuraremos observar, um estado anuncia a presença do outro, de modo que para se chegar à Identidade Moral faz-se necessário um processo de maturação que vai exatamente culminar com a maturidade moral. Isto é o que se tem como noção primária, a partir do qual aprofundaremos a reflexão, com o apoio da literatura pertinente. Para nos guiarmos no desenho deste citado retrato, é preciso descobrir traços subjacentes de sustentação. Para isto, nos perguntamos ainda: A maturidade moral se apresenta segundo determinados critérios? Q uais? Há indicadores que ofereçam maior ou menor confiança para que este retrato se apresente com maior nitidez?

$\mathrm{Na}$ linguagem corriqueira é costume se dizer que uma pessoa tem moral. Às vezes até mesmo se nota a referência a uma pessoa que tem uma Identidade Moral.

Pode-se afirmar que alguém, uma vez alcançada a maturidade moral, tem uma Identidade Moral? O verbo "ter" não nos parece o mais apropriado, pois não se trata precisamente de uma questão de posse, mas de essencialidade e de existência conjuntamente. Trata-se, pois, de uma séria preocupação no contexto dos estudos de Educação Moral, ainda recente, mas que se impõe a cada dia. A hipótese central de nosso estudo é a existência possível de uma relação entre as atividades pedagógica e a Identidade Moral. Podemos dizer, entre a prática pedagógica e a aquisição da Identidade Moral, feita a ressalva quanto à ambiguidade da palavra aquisição.

0 que nos interessa mais fortemente é a questão da presença do ato educativo neste processo. Pretendemos enxergar a relação entre a Educação e esta Identidade Moral, tomando-se neste momento a

Rev. Diálogo Educ., Curitiba, v. 9, n. 28, p. 633-649, set./ dez. 2009 
Educação sistemática, intencional e institucional que ocorre na escola. Chegar à construção de uma Identidade Moral não é resultado de uma evolução natural, nem de modo algum uma manifestação instintiva ou espontânea. Esta é uma das pedras assentadas na base de toda a nossa pesquisa sobre 0 assunto. Se considerássemos a Identidade Moral como algo decorrente de um amadurecimento predeterminado, não caberia aqui a análise que se esboça desde 0 título enunciado. Nem mesmo um amadurecimento biológico está sendo cogitado. A Identidade Moral não tem nenhuma analogia com qualquer forma de amadurecimento biológico, seja este qual for. 0 pressuposto de que a Identidade Moral tem forte conexão com o processo educativo é primordial em nossa discussão. Mais que isto, a Identidade Moral depende do que acontece na prática pedagógica, do que a escola pode oferecer em complementação à Educação iniciada, e continuada, na família e pela família.

Em razão não só da complexidade do tema, mas também pela necessidade de maior número de pesquisas sobre o assunto, nós estamos motivados para o debate sobre esta importante questão. Propomos, em vez de um item com as costumeiras conclusões, que façamos Reflexões Finais. Convidamos todos os interessados para uma participação ativa neste estudo, deixando o caminho aberto para as subseqüentes pesquisas.

Esta informação se faz necessária na medida em que apenas iniciamos uma pesquisa de $\operatorname{campo}^{3}$ visando observar a presença da Identidade Moral em jovens alunos do Curso Médio voltado para a formação profissional do professor para as quatro primeiras séries do Ensino Fundamental. 0 presente artigo surge como uma resposta à necessidade de maior fundamentação teórica sobre o assunto e também de uma reflexão mais profunda que possa auxiliar no aproveitamento dos dados que resultarão das observações empíricas.

Exatamente porque ainda não se tem um material satisfatório, e por não haver uma análise que possa levar a inferências e resultados, mais ainda se faz necessário o debate sobre o tema em questão. D entro de um contexto mais amplo dos estudos sobre Ética e também de Educação Moral, situa-se a construção da Identidade Moral ainda como uma indagação. É neste sentido que entendemos a necessidade de um maior número de estudos sobre Identidade Moral, principalmente porque:

Considera-se que a finalidade da vida é a felicidade, cuja obtenção exige a capacidade, como poderíamos dizer em terminologia moderna, de se adaptar ao próprio ambiente

Pesquisa do GPEE de 2007.

Rev. Diálogo Educ., Curitiba, v. 9, n. 28, p. 633-649, set./ dez. 2009 
da maneira mais efetiva consistente tanto com a natureza humana em geral como com as próprias características pessoais. Isto envolve entender como o cosmo funciona e também a natureza do próprio eu e do próprio papel na sociedade. 0 desenvolvimento de certas excelências de caráter e da mente, ou virtudes, tais como o controle dos desejos físicos e das emoções, a coragem e especialmente sabedoria, é de importância fundamental (HALLPIKE, 2004, p. 289).

Entende-se então a responsabilidade do educador na tarefa da construção da Identidade Moral das crianças e dos adolescentes. A escola não pode fugir desta função à qual é chamada pela família em particular e pela sociedade como um todo.

\section{Maturidade ética e identidade moral: uma discussão pedagógica}

Se pretendermos trabalhar o conceito da expressão Identidade Moral, faz-se necessário em primeiro lugar um estudo detalhado de cada uma das palavras que a compõem. D este modo, procuraremos neste item, de forma separada, enfocar o conceito de Identidade e em seguida o conceito de Moral. Isto se torna extremamente importante, porque é a base de sustentação das ideias que podem ser construídas.

0 que é a Identidade? A identidade de uma pessoa pode ser entendida como o efeito visível de toda a sua vida psíquica, desde a mais tenra infância até aquela etapa em que se olha no interior de si mesmo, toma consciência de quem é na realidade e se verifica único diante do outro. Esta separação, que não significa isolamento, pois só será possível pela interação social, demonstra a conclusão de todo um processo de construção psíquica para no qual a prática pedagógica exerce um papel fundamental. 0 ser humano se exige como uma consciência individual simultaneamente à sua significação como ser que se organiza coletivamente. To das as atividades de sua vida acontecem na tensão deste paradoxo, de modo que se torne possível uma identidade construída, a qual não lhe é oferecida nem imposta, mas algo resultante de sua ação particular e social. Quando afinal um jovem adulto se reconhece como um sujeito separado de outras coisas e de outras realidades, das outras pessoas e de outras ideias, ele se torna um ser humano em sua identidade.

Rev. Diálogo Educ., Curitiba, v. 9, n. 28, p. 633-649, set./ dez. 2009 
Podemos nos perguntar, então, quais as bases de formação desta identidade. 0 mapeamento do genoma humano não indica nenhum gene da identidade, seja no sentido mais amplo, da identidade como um todo que marca aquele indivíduo, ou, mesmo, visto em suas facetas específicas, tal como é o caso da identidade moral. Não temos subsídios biológicos, até 0 momento, que nos revelem o que éa identidade segundo esta ciência. Não sabemos se um dia encontraremos informação adequada e suficiente que nos ensine o que é a identidade do ponto de vista biológico.

Estudosbuscam entendero queéaidentidadeapartirdemanifestações comportamentais, principalmente, sem, no entanto, se prenderem a teorias comportamentais. Estas manifestações são as pistas iniciais que devem nos levar às bases que as originaram. Q uais são os pensamentos primeiros que um sujeito tem sobre si mesmo? Q uais são os sentimentos, positivos e negativos, que são gerados no interior do sujeito, mesmo que provocados por estímulos externos, e que se traduzem em tais comportamentos?

Numa perspectivaintegradora, pesquisando o desenvolvimento cognitivo do adolescente, Inhelder ePiaget (1976) observaram ainteração social como imprescindível para a plenitude do pensamento lógico abstrato, concluindo que este não se realiza se o jovem não estiver previamente socializado. 0 desenvolvimento da identidade do sujeito é dependente de todas as suas capacidades de forma conjunta.

Assim é preciso que estejamos atentos sempre ao todo da pessoa, observando suas características biológicas, afetivas, cognitivas esocioculturais em desenvolvimento. Que indicadores definem o conceito de Identidade? Esta é a preocupação constante que nos guia em nossas pesquisas, principalmente porque sabemos que indicadores fixos ainda não existem. Buscamos organizar protocolos, dentro da flexibilidade necessária e inerente a um conteúdo deste tipo, no entanto, estes ainda não existem de forma satisfatória. Um dosmais conhecidos estudos sobreadolescentequeapresenta uma lista de tarefas a serem vencidas pelos jovens para que alcancem sua maturidade é Robert Havighurst (1958), cujos pioneiros trabalhos são considerados clássicos. O citado autor sededicou ao tema em diferentes obras nas quais se pode encontrar boa orientação para esta perspectiva, que são sempre referenciadas por estudiosos do assunto, entre os quais Muus (1973).

Formação da Identidade é um problema educacional?

Sem dúvida que a formação da Identidade é um problema educacional, principalmente quando se entende que ninguém nasce com a própria identidade definida. $O$ se conhecer a si mesmo é uma tarefa complexa que exige a cooperação de muitas pessoas. Neste sentido é que Alasdair MacIntyre (1999) chama a atenção para a nossa

Rev. Diálogo Educ., Curitiba, v. 9, n. 28, p. 633-649, set./ dez. 2009 
dependência, como animais racionais e éticos. Em obra filosófica anterior, de grande impacto entre estudiosos de moral, MacIntyre (1984) se refere à virtude como a habilidade necessária para a vivência ética. Esta habilidade será adquirida por meio da educação desde 0 início da vida do sujeito (LINS, 2004, p. 3).

Esta é uma perspectiva importante que não pode ser perdida pelo educador em sua atividade pedagógica. Por meio das diversas práticas curriculares, o aluno desenvolverá a sua maturidade plena, incluída nesta, de forma necessária, a identidade moral.

Tendo sido apresentadauma reflexão maisgeral visando estabelecer o que se entende por Identidade, passamos agora a um conceito mais específico na medida em que buscamos saber o que é Identidade Moral. Segundo Pfromm Netto (1976, p. 274), numa afirmativa que se mantém atual, "incertezas, contradições, conflitos e rebeliões no domínio dos padrões morais parecem sercomunsnosanosdaadolescência". Constatandose a exatidão desta afirmativa em nossas contínuas visitas a escolas, supervisões, pesquisas e contatos em geral com jovens, maior ainda é a necessidade de se entender a questão da Educação e da Identidade Moral.

\section{Q ual a relação entre E ducação e Identidade Moral?}

A primeira ideia que surge é a aproximação entre um processo e um produto. A Educação é um processo de aperfeiçoamento de cada ser humano, de modo que passe de um estado menos acabado para estados cada vez mais sofisticados em sua totalidade. Por isso a E ducação interfere no desenvolvimento geral do indivíduo, favorecendo sua escalada a níveis mais altos, demonstrando cada vez maior capacidade. $\mathrm{Na}$ medida em que prossegue, o ser humano se observa como uma pessoa que ultrapassa fronteiras, estabelece novas metas e continua sempre em frente, rumo novas e melhores formas. Isto tudo porque 0 ser humano é rico em possibilidades e passa do potencial para o ato, criando e transformando o mundo a sua volta. A Educação é o processo quelhe permiteum desempenho melhor porque esteé uma demonstração de alguém que se torna cada vez melhor. Se falarmos em passagem para algo melhor é porque estabelecemos graus de comparação e critérios de avaliação. Durante toda a vida, cada um dos indivíduos está vivendo segundo elementos de comparação, consigo próprio, principalmente, e com as outras pessoas. A psicologia se organizou como ciência, se bem que não uma ciência no sentido positivista, mas uma ciência, porque usa

Rev. Diálogo Educ., Curitiba, v. 9, n. 28, p. 633-649, set./ dez. 2009 
método científico e neste está o trabalho de análise de grupos para verificação de semelhanças e diferenças.

Durante o processo de Educação, podemos destacar determinados momentos que têm maior significação epor serem aquisições da maior importância podem ser considerados produtos. São cortes no processo que expõem certas capacidades construídas, e, por isso mesmo, resultantes de construção e não mais em construção. Trata-se de uma perspectiva dinâmica na qual são feitos estes cortes. Com esta explicação chegamos ao conceito de Identidade Moral. Identidade Moral é um produto de um longo processo que abrange a complexidade do desenvolvimento cognitivo, afetivo e social também. Não mais se trata de um dever ser ou de uma corrida visando um ponto de chegada. A Identidade é o que o sujeito é. Para isto ele passou por um longo processo de maturação, em diferentes enfoques. Houve um processo de maturação biológica, o qual é o mais independente de sua própria ação, apesar de que é sempre possível a interferência do sujeito, desdea escolha do tipo de sua alimentação ao uso de drogas e outros materiais deletérios.

\section{Como alguém se percebe como um eu? Como um eu moral?}

O grande filósofo francês do século XX, Jacques Maritain (1951), desenvolveu um profundo estudo sobre este tema, dentre outros por ele analisados, salientando sempre a imprescindível necessidade de alguém se perceber como um eu. Nesta percepção está a intuitiva consciência de si mesma como pessoa única, dotada de privacidade e de liberdade, de dignidade e de capacidade moral. 0 estudo da subjetividade realizado por Maritain foi comentado por vários autores, entre eles Bars (1975) e Lacombe (1975), que enfatizam a importância da identidade completa da pessoa como consciência que orienta sua própria vida.

Assim, uma pessoa é uma Identidade Moral. Uma pessoa alcançou um estado superior no processo de sua autoconstrução que 0 faz ser conhecido como uma Identidade Moral. D urante a adolescência, as emoções e sentimentos ocupam um lugar preponderante na vida da pessoa e agem sobre seu desenvolvimento. A construção dos valores se apresenta, em conjunto com a organização pessoal das emoções e sentimentos, como um elemento crucial na vida do adolescente. Valores são bens específicos, aos quais alguém confere uma especial atenção e são considerados por esta pessoa como fundamentais (LINS, 1999).

Rev. Diálogo Educ., Curitiba, v. 9, n. 28, p. 633-649, set./ dez. 2009 
Muitas vezes se fala em perda de identidade ou ausência de identidade, do jovem ou mesmo das pessoas mais velhas. Nestes casos, como Hude (1992, p. 95) alerta: "tendo-se em conta a necessidade de identidade de todo homem, o risco é de ver a reidentificação mais pobre, isto é, aquela que consiste, para um homem, em se identificar pelo simples fato de não ser o outro considerado em sua aparência". I Identidade Moral é o que a pessoa é como resultado da seleção dos valores éticos fundamentais ao seu ser. No início da adolescência, quando começa a pensar sobre si e os outros, segundo a nova capacidade das estruturas lógico-formais, o jovem descobre, entre outras coisas, que sua fala e seu agir geram diferentes consequências e são avaliadas diferentemente pelos outros. O u o jovem vai se tornar uma marionete nas mãos de quem o ouve ou passa a se guiar por valores, os quais devem sustentar o seu ser independentemente do que provoque nos outros. É nesta perspectiva que Raissa Maritain (1954) define Jacques Maritain como uma pessoa que não tinha respeito humano, isto é, não se guiava em suas decisões pelo que os outros pensariam sobre ele. Isto revela uma Identidade Moral firme e corajosa. Este é o caminho que deve ser procurado.

Lembremo-nos principalmente da perspectiva de Aristóteles (1965) ao afirmar que o destino da pessoa é ser feliz e que a felicidade se alcança pela vivência das virtudes. D este modo é preciso que uma pessoa se entenda em primeiro lugar como tal e faça a opção da vida das virtudes a partir de sua maturidade ética. Esta conquista vem sendo estudada ao longo de toda a história da filosofia, e principalmente da psicologia, com suas contribuições so bre o significado da personalidade. Dentre os estudos mais importantes, destacamos a obra de Erikson (1972) que analisa a conquista da identidade por meio da passagem de estágios crescentes, nos quais a crise tem fundamental papel. Para este autor, a identidade será adquirida no final da juventude, depois da experiência de conflitos e desequilíbrios que incluem principalmente a capacidade de superar frustrações.

D epois de seus estudos especificamente direcionados para a construção da identidade e entendendo que esta deve estar concluída no jovem adulto, este mesmo autor continuou suas pesquisas prolongando a observação a outros estágios e chegando até a idade mais avançada, elaborando quadros que mostram a identidade do idoso. Assim lembra que depois dos anos pré-escolares e dos conflitos da adolescência, a maturidade adulta se apresenta com a integridade como a principal característica. Sobre esta, diz Erikson (1998, p. 55) "A integridade, todavia, parece transmitir uma exigência peculiar - como transmite a

Rev. Diálogo Educ., Curitiba, v. 9, n. 28, p. 633-649, set./ dez. 2009 
força específica que postulamos como amadurecendo a partir da última antítese - a sabedoria." Para este pesquisador, a excelência da maturidade se encontra na realização da identidade no nível da sabedoria.

A contribuição de suasúltimas pesquisas aponta para a sabedoria moral como a característica fundamental da pessoa nos últimos estágios do ciclo da vida.

\section{REFLEXÕES FINAIS}

Muito há ainda a ser buscado para que realmente possamos dizer o que éa Identidade Moral de modo mais preciso e como se pode favorecer a sua construção pela prática pedagógica. A discussão aqui apontada é apenas o início de um caminho indispensável para todos os educadores, quaisquer que sejam suas especializações. Podemos, no entanto, apresentar algumas reflexões que nos indicam uma possibilidade educativa escolar. Conhecendo-se a presença de um eu próprio que existe ontologicamente e biologicamente desde a concepção de cada ser humano, devemos partir para o processo educativo no sentido de oferecer as condições para que seja cada vez mais aperfeiçoado, o que acontece no meio psico-social-cultural. A identidade deve ser entendida em sua paradoxal composição, de ser que já é, ao mesmo tempo em que é um ser que deve ser. A identidade moral atingirá sua plenitude no que se chamou aqui a maturidade moral, ou seja, o patamar em que o sujeito atinge o domínio de sua autoconsciência, a elaboração de uma hierarquia de valores e age conforme paradigmas que lhe propiciam o livre discernimento para o seu agir.

A importânciadareflexão sobreIdentidadeMoral exigedo professor um aprofundamento nas questões sobre a pessoa do aluno e os princípios filosóficos, principalmente concernentes à ética eà prática em sua vida moral. Lembremo-nos que "todas as faculdades ativas do homem concorrem para a realização dos atos morais", conforme ensina Tomas de Aquino (1998, p. 160), e estes atos morais serão a manifestação da maturidade de uma pessoa que utiliza todas as suas capacidades neste sentido.

É importante ainda enfatizar que o tempo da adolescência é privilegiado e único no que diz respeito à construção da Identidade Moral. Privilegiado porque nele acontecem os conflitos profundos que exigem uma solução, e único porque possibilitam ao adolescente um mergulho em sua consciência, a viagem mais importante que fazem, adiando por algum tempo compromissos que serão assumidos na idade adulta. Nem na infância, por ser ainda o sujeito incapaz de formas de pensamento e de socialização adequadas, nem na idade adulta, por

Rev. Diálogo Educ., Curitiba, v. 9, n. 28, p. 633-649, set./ dez. 2009 
comprometimentos outros, é possível se encontrar um terreno tão fértil para que se organize uma prática pedagógica possível de frutificar neste sentido. A Educação do jovem deve ser então voltada para esta finalidade, reforçando a perspectiva de Maritain (1959) ao afirmar que os fins da educação devem estar sempre norteando to da ação pedagógica, sem que sejam substituídos pelos meios ou simplesmente abandonados.

Sintetizando as reflexões aqui apresentadas, entendemos que Identidade Moral não é um dom ou uma característica natural no ser humano, mas algo conquistado ao longo de um determinado período da vida e que deve ser aperfeiçoado continuamente, para que a idade da velhice seja atingida com sabedoria e não com as características de desespero e estagnação. Assim, a Identidade Moral, como a Identidade num sentido amplo, de modo algum é constituída por traços genéticos ou adquirida de forma pronta e acabada por qualquer meio que seja. A Identidade Moral é uma conquista do próprio sujeito, somente dele, por seu esforço e seus progressos na busca por um estabelecimento completo e total do seu eu. A parece então a figura do educador como aquele que encaminhará o sujeito, apontando-lhe elementos para que ele possa fazer as escolhas ditadas por sua consciência retamente formada.

A Identidade Moral se alinha às outras facetas deste ser, de modo que temos também neste conjunto os aspectos cognitivos, afetivos e sociais, formando a personalidade. Não se pode compreender a Identidade Moral de forma isolada, pois esta se consolida a partir de construções conjuntas do ser humano que é cognitivo, afetivo e social.

O bservamos ainda que a Identidade Moral, não sendo um dom ou uma característica natural, precisa e deve ser construída. Esta construção não acontece de modo aleatório, pelo contrário, exige um projeto educativo amplo, calcado em valores e organizado segundo fins de aperfeiçoamento do indivíduo. Isto principalmente quando se sabe da enorme dificuldade que o ser humano hoje encontra na compreensão do que são as virtudes que devem compor a sua Identidade Moral, pela decadência da sociedade e pela constante troca das antigas virtudes por novas virtudes, estas últimas nem sempre propriamente virtudes, como lembra Anderson (2005). 0 que é oferecido hoje ao jovem no lugar das virtudes não tem condição de lhe propiciar a construção de sua Identidade Moral, por isto ele está confuso e se mostra perdido, como numa encruzilhada e sem o mapa da região.

É por meio da Educação que se forma a pessoa integralmente. A Educação em seu sentido mais extenso, iniciada na família e acrescida das diferentes estâncias quepara esteprojeto devem concorrer. D estacamos

Rev. Diálogo Educ., Curitiba, v. 9, n. 28, p. 633-649, set./ dez. 2009 
dentre estas, a Escola, instituição na qual a Educação deve ocorrer de forma sistematizada e com objetivos claros e definidos, dentre os quais a formação moral da pessoa. Neste sentido Giussani (1995) mostra como a educação é um chamado à pessoa para que livremente ela tenha um encontro consigo mesma e com os valores transcendentais.

Escolas devem programar a Educação Moral com a finalidade de oferecer aos estudantes a oportunidade de construir sua Identidade Moral. Seja qual for a metodologia utilizada, ou qual a proposta curricular vigente, a E ducação Moral é indispensável, pois ética se aprende desde a infância. A conclusão deste processo existe, ela se dá com a Maturidade Moral que revela exatamente a Identidade Moral. Não podemos cair no erro de um pragmatismo indefinido que não considera etapas conclusivas durante o processo de formação da personalidade. Voltamos a destacar a importância dos patamares de conquistas na progressão da vida dos indivíduos, principalmente aquele da maturidade no final da adolescência, no qual o sujeito passa a se apresentar com a sua identidade.

Podemos dizer que há Identidade Moral quando uma pessoa rege sua vida em conformidade com os valores morais, isto é, que sua vida revela uma pessoa particular e cônscia de seu eu único e irrepetível. Assim é que esta pessoa está consciente de sua responsabilidade completa, no sentido mais profundo, quanto a todos os seus pensamentos e atos. Suas decisões são resultado de escolhas particulares, calcadas em critérios que foram selecionados não segundo modismos ou influências quaisquer, mas sim como conclusões de suas reflexões e análises. D este modo a sua vida não mais se desenrola ao acaso, como acontece na infância, até na adolescência, e nos adultos que não chegaram à construção de uma identidade moral.

A partir daidentidade moral, o sujeito tem a sua vida configurada de acordo com a ética. A presença da Identidade Moral demonstra que uma pessoa desenvolveu a maturidade ética. Revela ainda o caráter desta pessoa, aquilo de mais profundo que existe como resultado também de uma construção pessoal. D este modo sabemos que a prática pedagógica foi bem sucedida, pois atuou de modo a contribuir para que um sujeito inicialmente amoral se tornasse uma pesso a dotada de identidade moral.

É importante que se entenda a Identidade Moral como necessariamente vinculada à Identidade que nos faz reconhecer uma pessoa como tal. Pode-se entender a Identidade como um conjunto mais amplo no qual está contida a Identidade Moral, o que implica no desenvolvimento pleno da Identidade para que também a Identidade Moral seja construída. Assim, o trabalho educacional primário se refere à própria construção da Identidade, estendendo-se este com a finalidade

Rev. Diálogo Educ., Curitiba, v. 9, n. 28, p. 633-649, set./ dez. 2009 
de também permitir ao sujeito alcançar a sua Identidade Moral. Consideramos que a Identidade de alguém não está perfeitamente construída se lhe faltam as características que permitem indicar a presença da Identidade Moral. É por isso que tivemos o objetivo de apresentar aqui as reflexões so bre a natureza, o processo e a necessidade da prática pedagógica para que se consiga estabelecer esta importante faceta do ser humano, a sua Identidade Moral.

\section{REFERÊNCIAS}

ANATRELLA, T. Interminables adolescences, les 12-30 ans. Paris: Ethique \& Société - Cerf/ Cujas, 1991.

AND ERSO N, D. Decadence: the passing of personal virtue and its replacement by political and psychological slogans, the social affairs unit. London: Crowley Esmond, 2005.

AQUINO, T. Textes sur la morale. Paris: Librairie Philosophique, 1998.

ARISTÓTELES. Étique à nicomaque. Paris: Flammarion, 1965.

BARS, H. Sujet et subjectivité selon Jacques Maritain. Les É tudes Philosophiques, Paris, p. 31-46, janv./ mars 1975.

ERIKSO N, E. H. Identidade, juventude e crise. Tradução de Álvaro Cabral. Rio de Janeiro: Zahar, 1972.

. 0 ciclo de vida completo. Tradução de Maria Adriana Veronese. Porto Alegre: Artmed, 1998.

G IUSSANI, L. Il rischio educativo. Torino: Società E ditrice Internazionale, 1995.

HALLPIKE, C. R. The evolution of moral understanding. Alton: Prometeus Research Group, 2004.

HAVIG HURST, R. O desenvolvimento da personalidade moral. Educação e Ciências Sociais, São Paulo, n. 8, p. 11-129, 1958.

HART, D. The development of moral identity. In: NEBRASKA SYMPO SIUM ON MOTIVATION GENDER AND MOTIVATION, 45., 1997. Nebraska. Proceedings... Nebraska: University of Nebraska Press, 1997. p. 165-196.

HUD E, H. É thique et politique. France: Universitaires France, 1992.

Rev. Diálogo Educ., Curitiba, v. 9, n. 28, p. 633-649, set./ dez. 2009 
INHELDER, B; PIAGET, J. Da lógica da criança à lógica do adolescente. Tradução e D ante Moreira Leite. São Paulo: Pioneira, 1976.

LACO MBE, O. J. M. et al. Philosophie de l'être. Les E tudes Philosophiques, Paris, p. 69-78, 1975.

LINS, M. J. S. C. Educação e contemporaneidade: educação Moral na encruzilhada. Revista da FAEEBA, Salvador, ano 8, n. 12, p. 97-112, 1999.

Ética se aprende na infância. Cátedra, Rio de Janeiro, p. 3, 08 fev. 2004. Caderno 14.

MACINTY RE, A. Aftervirtue. 2nd ed. Indiana: University Notre D ame Press, 1984.

Dependent rational animals why human beings need the virtues. Chicago: Open Court, 1999.

MCD ONOUGH, G. P. Moral maturity and autonomy: appreciating the significance of lawrence kolhberg's just community. Journal of Moral Education, v. 34, n. 2, p. 199-213, 2005.

MARITAIN, J. Rumos da educação. Rio de Janeiro: Agir, 1959.

Introdução geral à filosofia. Rio de Janeiro: Agir, 1968.

Neuf leçons sur les notions premières de la Philosophie Morale. Paris: Chez Pierre Tequi, 1951.

MARITAIN, R. As grandes amizades. Rio de Janeiro: Agir, 1954.

MUUS, R. Teorias da adolescência. 3. ed. Belo Horizonte: Interlivros, 1973.

PFRO MM NETTO, S. Psicologia da adolescência. São Paulo: Pioneira; Brasília: MEC, 1976.

Recebido: 10/ 11/ 2008

Received: 11/ 10/ 2008

Aprovado: 02/ 12/ 2008

A pproved: $12 / 02 / 2008$

Revisado: 14/ 09/ 2009

Reviewed: 09/ 14/ 2009

Rev. Diálogo Educ., Curitiba, v. 9, n. 28, p. 633-649, set./ dez. 2009 